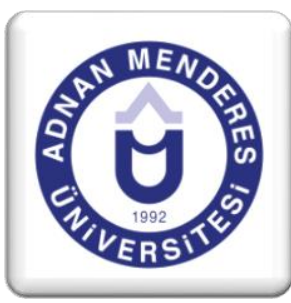

\section{Turizm Sektöründe Araç Rotalama Problemi Ve Karar Destek Sistemi Uygulaması $^{1}$}

\author{
Mehmet AKSARAYLI' ${ }^{2}$, Osman PALA ${ }^{3}$, Ayşegül \\ CENGER $^{4,}$ Yasemin ÖZL ${ }^{5}$, Mehmet Akif AKSOY
}

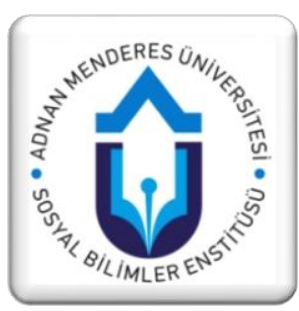

\title{
ÖZET
}

Çalışmanın amacı, turizm sektöründe kendisine ait bir araç filosu ile altmış adet otele hizmet veren bir ulaşım firması için önceden belirli otel ve otelden havalimanına gidecek müşteri sayılarına göre oteller ve havalimanı arasında yapılacak turların güzergahlarını en kısa sürede gerçekleşecek şekilde belirlemektir. Çalışmada sadece örnek durumlar için çözüm üretmekle sınırlı kalmayıp, firma için kullanabileceği bir karar destek sistemi oluşturmak ve firmanın elinde bulunan araç filosunun verimini arttırarak gün içinde daha çok tur yapabilme kapasitesine kavuşmasını minimum toplam süre ile sağlamak ve bir yolcunun ortalama ulaşımda geçirdiği süreyi azaltarak firmanın ulaşım hizmetine duyulan memnuniyeti arttırmak öncelikli hedef olarak belirlenmiştir. Problem Kapasite Kısıtlı Araç Rotalama problemi olarak bazı ek kısıtlarla birlikte kesin çözüm verecek şekilde Tamsayılı programlama yaklaşımı ile modellenmiştir. Her biri yirmişer defa olacak şekilde 10 ve 15 otelli tur güzergahları simülasyon yoluyla oluşturulmuş ve firmanın kendi güzergahları ile karar destek sisteminden elde edilen turların süresi ve ortalama ulaşımda geçirilen süre karşılaştırılmış ve önerilen modelin her iki parametre açısından da önemli iyileştirmeler sağladığı gözlenmiştir.
Anahtar Kelimeler
;Araç rotalama, Tamsayılı Programlama, Karar Destek Sistemi.

Jel Kodları

;C610, C100, C630

\section{A Vehicle Routing Problem In Tourism Sector And Implementation Of A Decision Support System}

\begin{abstract}
The aim of the work is to provide minimum duration for the route of the tours to be made between hotels and the airport for predetermined number of customers of a transportation company that serves 60 hotels with a car fleet of its own in the tourism sector. To provide solutions that is not limited to sample tours in the study, it is necessary to provide a decision support system that can be used for the firm and to increase the efficiency of the vehicle fleet in the hands of the firm and to increase the capacity to make more tours in the day with minimum total time and decrease the passenger's average transportation time. Increasing the satisfaction level has been determined as the primary objective. Problem is modeled as a Capacitated Vehicle Routing Problem with Integer Programming approach which gives a definite solution together with some additional constraints. Ten, fifteen and twenty tour routes were created by simulation, each of which was ten times, and the duration of the tours and the average time spent on the route were obtained both from the decision support system and firm's tours that they planned as oldschool were compared and the proposed model provided significant improvements in terms of both parameters.
\end{abstract}

Keywords ;Vehicle Routing, Integer Programming, Decision Support System.

Jel Codes $\quad$; C610, C100, C630.

\footnotetext{
1 Bu çalışma EUREFE 2017'de bildiri olarak sunulmuştur.

2 Dokuz Eylül Üniversitesi İktisadi ve İdari Bilimler Fakültesi Ekonometri Bölümü, 0 (232) $301 \quad 02 \quad 81$, mehmet.aksarayli@deu.edu.tr

3 Dokuz Eylül Üniversitesi İktisadi ve İdari Bilimler Fakültesi Ekonometri Bölümü, 0 (232) 30102 71, osman.pala@deu.edu.tr

4 Dokuz Eylül Üniversitesi Sosyal Bilimler Enstitüsü Ekonometri Yüksek Lisansı

5 Dokuz Eylül Üniversitesi Sosyal Bilimler Enstitüsü Ekonometri Yüksek Lisansı

6 Dokuz Eylül Üniversitesi Sosyal Bilimler Enstitüsü Ekonometri Doktora
} 


\section{Giriş}

Günümüzde araç rotalama problemi (ARP), ulaşım sektöründe sıklıkla kullanılmaktadır. Ulaşım sektörü, turizmin canlandığ 1 yaz sezonunda rol oynayan en önemli sektörlerden biridir. ARP'yi en basit tanımıyla, bir merkezde bulunan m adet aracın farklı miktarlardaki malları $\mathrm{n}$ adet müşteriye dağıtması olarak açıklamak mümkündür.

Klasik ARP, talepleri bilinen müşteri kümesine hizmet veren bir grup aracın dağıtımı gerçekleştirdikten sonra merkeze geri dönmesini sağlayacak en uygun güzergâhın belirlenmesi esasına dayanmaktadır. Burada amaç bu dağıtımı gerçekleştirirken oluşan tüm taşıma maliyetlerinin minimize edilmesidir.

Klasik ARP çözümü, aynı tip ve kapasiteye sahip homojen bir araç filosu için bir depoda başlayıp yine aynı depoda biten ve her müşteriye yalnızca bir kez hizmet verilmesine olanak sağlayan bir dizi rotanın oluşturulmasıdır.

ARP firmanın sahip olduğu araçların, firmanın merkezinden, talepleri önceden bilinen müşteri kümesine hizmet edip tekrar merkeze dönmesini sağlayacak en kısa süreli rotaların bulunması problemidir (Yücenur ve Çetin Demirel, 2011: 341).

Turizm sektöründe Karagül ve Güngör (2014a) yaptıkları çalışmada klasik araç rotalama ile acentenin dört tip araç kullanmak yerine temini daha kolay olduğundan yeni bir plan ile tek tip (46 kişilik) araç kullanması önerilmiştir. Üç parçadan oluşturulan 500 birimlik uzayın bir parçası Tasarruf Algoritması, bir parçası Süpürme Algoritması ve kalan kısmı Rassal Arama Yaklaşımı ile elde edilmiştir. Karşılaştırma sonucunda Rassal Arama Yaklaşımı en iyi çözümleri vermiştir.

Gezgin Satıc1 Problemi (GSP) şeklinde çözülen bir problemi ARP'ye dönüştürerek çözmek boyut gereği daha zordur. Örneğin, çok sayıda lokasyon bulunan bir GSP ileri düzeyde DalKesme algoritmaları ile uygun zaman diliminde çözülebilmektedir. Ancak, ARP için geliştirilmiş olan çok daha karmaşık kesin matematiksel algoritmalar en fazla 100 lokasyona kadar olan örnekleri başarılı bir şekilde çözebilmektedir. Bu nedenle araştırmacıların çoğu sezgisel yöntemlerle çalışmaya yoğunlaşmaktadır. Araştırmacıların Sezgisel Algoritmalara yönelmesinin başka bir sebebi, sezgisel yöntemlerin kesin matematiksel yöntemlerden daha kolay kullanılabilir olmasıdır.

Karagül ve Güngör (2014b) çalışmalarında bir ulaşım firmasının veritabanından 8 tane örnek dağıtım planı almışlardır. Başlangıç populasyonlarını Tasarruf Algoritması, Süpürme Algoritması ve Rassal Permütasyon Algoritmasını kullanarak oluşturmuşlardır. Çözüm metodu olarak ise Standart Genetik Algoritma ve Rassal Arama Algoritması kullanmışlardır. Sonuçlara göre Genetik Algoritma çözüm kalitesi açısından daha kötüdür ve çözüm süreleri daha uzundur. Rassal Arama Algoritmasının maliyet ve süre bakımından daha etkili bir yöntem olduğu gözlenmiştir.

Çalışmada İzmir/Çeşme'de hizmet veren bir ulaşım firmasının havalimanına gidecek rezervasyonlu yolcuları için yapılacak seferlerin güzergahlarını, müşteri memnuniyetini sağlamak ve yakıt maliyetlerini azaltmak amacıyla minimum sürede gerçekleştirmek amaçlanmıştır. Önceden belirlenmiş otellerden uçak saatleri birbirine yakın olan yolcuların aynı araca toplanarak, havalimanına uçak saatinden en az 1 saat önce varması için bir rota çizilmesi gerekmektedir. Problemde, her otel sadece bir araçtan hizmet almakta ve her araç sadece bir rota izlemektedir. 


\section{Araç Rotalama}

ARP ilk olarak Dantzig ve Ramser (1959) tarafından genelleştirilmiş GSP olarak ifade edilmiş, bir gerçek hayat problemi olan terminalden akaryakıt istasyonlarına benzin dağıtımı için modellenmiş ve probleme özgün oluşturulmuş algoritmaya dayalı bir yaklaşımla çözüm elde edilmiştir. 1964'te Clarke ve Wright, etkili bir sezgisel yaklaşım prosedürü kullanarak farklı araç kapasiteleri ve müşteri talepleri için ARP çözüm yaklaşımını geliştirmişlerdir.

İlk defa ARP için "araç rotalama" ifadesini Golden vd. (1972) çoklu depo rotalama algoritması geliştirdikleri çalışmada kullanmışlardır. Levin (1971) çalışmasında filo büyüklüğü rotalama problemini tam sayılı programlama olarak modellemişlerdir. Golden ve Stewart (1978) çalışmalarında stokastik talebe göre ARP çözüm algoritması geliştirmişlerdir. Solomon (1983) ARP'ye zaman bağımlı kısıtlar eklemiştir. Buna göre araçlar belirli noktalara belirli zaman dilimleri içerisinde uğramalıdır.

Çok sayıda ARP çalışmasını inceleyen Laporte (1992) kesin çözüm sunan algoritmaları üç sınıfa ayırmış ve direkt arama ağacı algoritması, dinamik programlama ve doğrusal tam sayılı programlara olarak adlandırmıştır. Detaylı ARP literatür çalışması, Eksioğlu vd. (2009) tarafından sistematik bir şekilde yapılmıştır.

\subsection{Kapasite Kısıtlı Araç Rotalama}

Kapasite kısıtlı araç rotalama problemi (KKARP), ARP'nin önemli parçalarından biridir. Genellikle rota mesafeleri ya da araç kapasiteleri kısıtlarıyla tanımlanan ARP sadece kapasite kısıtlarının tanımlanması durumunda KKARP olarak adlandırılmaktadır. $\mathrm{Bu}$ şekildeki problemlerin çözümü için geliştirilen yöntemlerde gerekli değişiklikler yapılarak mesafe kısıtını da dikkate aldıkları görülmektedir (Cordeau vd., 2004: 368).

Toth ve Vigo, (2002: 441) KKARP'de amacı talepleri bilinen müşterilere sadece bir defa uğranarak toplam hizmet maliyetini minimize etmek olarak tanımlarken, Lin vd. (2009: 1506) araçların kat ettiği toplam mesafeyi minimize etmek olarak ifade etmiştir. Laporte (1992: 345-346) KKARP'yi aşağıdaki üç adımda tanımlamıştır;

$>$ Rota üzerinde bulunan her şehir sadece bir araç tarafından ziyaret edilir,

$>$ Her bir rota depodan başlayıp yine aynı depoda sona erer,

$>$ Kapasite, toplam süre ve zaman penceresi ancak rotadaki şehirlerin toplam sayısı kadardır.

En basit şekliyle KKARP'de, her aracın kapasitesi eşit ve araçlar bir depodan harekete başlayıp rotasını tekrar aynı depoya dönerek tamamlamaktadır. Her bir müşterinin talebi tek bir seferde teslim edilmektedir. Müşteriler arasındaki karşılıklı gidiş gelişlerin simetrik kabul edildiği KKARP'de tüm araçların talepleri karşılaması için araç sayısı kadar rota bulunmaktadır. APR modellerine, başarmak istediğimiz amaçlar doğrultusunda her bir bileşene farklı kısıtlar ve durumlar eklenebilir ve bu şekilde farklı ARP türleri elde edilebilir.

Daneshzand (2011: 127-128) başlica ARP türlerini; Kapasite Kısıtlı Araç Rotalama Problemi (KKARP), Mesafe ve Kapasite Kisitlı ARP (MKARP), Zaman Pencereli ARP (ZPARP), Geri Toplamalı ARP (GTARP), Dağıtım ve Toplamalı ARP (GTARP), Açık Rotalı ARP (AARP),Çoklu Depolu ARP (ÇDARP), Bölünmüş Teslimatlı ARP (BTARP), Periyodik ARP (PARP) ve Bulanık ARP (BARP) olarak tanımlamıştır. Aşağıdaki Şekil 1'de ARP türlerinin birbiri ile olan ilişkileri gösterilmiştir 


\section{Şekil 1: ARP Türleri Arasındaki İlişki}

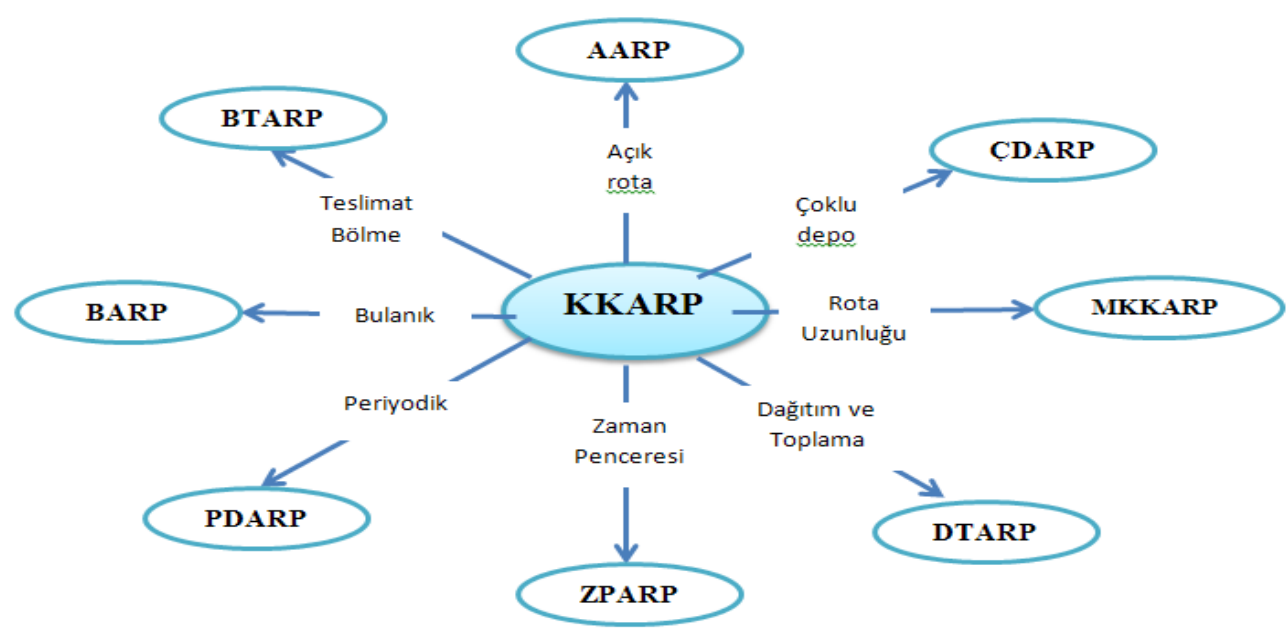

Kaynak: Şahin ve Eroğlu, 2014: 338.

Kara vd. (2004) tarafindan Miller-Tucker-Zemlin (MTZ) kısıtlarını kullanarak geliştirilen KKARP modeli aşağıdaki gibidir;

$$
\begin{aligned}
& m ı n \sum_{i \neq j} c_{i j} x_{i j} \\
& \sum_{j=2}^{n} x_{1 j}=m \\
& \sum_{i=2}^{n} x_{i 1}=m \\
& \sum_{j=1}^{n} x_{i j}=1 \quad(\mathrm{i}=2, \ldots, \mathrm{n}),(\mathrm{j} \neq \mathrm{i}) \\
& \sum_{i=1}^{n} x_{i j}=1 \quad(\mathrm{i}=2, \ldots, \mathrm{n}),(\mathrm{j} \neq \mathrm{i}) \\
& u_{i}-u_{j}+Q_{x_{i j}} \leq Q-q_{i} \quad(\mathrm{i}, \mathrm{j}=2, \ldots, \mathrm{n} ; \mathrm{j} \neq \mathrm{i}) \\
& q_{i} \leq u_{i} \leq Q \quad(\mathrm{i}=2, \ldots, \mathrm{n}) \\
& x_{i j}=0 \text { veya } 1 \quad(\mathrm{i}, \mathrm{j}=1, \ldots, \mathrm{n} ; \mathrm{j} \neq \mathrm{i}) \\
& m \geq 1 \text { ve tamsayl }
\end{aligned}
$$


Modeldeki (2.1) amaç fonksiyonu iken (2.2) - (2.5) kısıtlayıcıları düzey kısıtlayıcılarıdır. (2.6) ve (2.7)'deki kısıtlar gezgin satıcı problemi için önerilmiş olan MTZ alt tur eleme kısıtlayıcılarını genişleterek devam ettirir. (2.8) ve (2.9) modeldeki değişkenlere dair tam sayı sınırlamalarıdır. Modeldeki parametre ve değişkenler aşağıdaki gibidir;

$x_{i j}:$ i. noktadan j. noktaya geçiş yapılması.

$C_{i j}:$ i. noktadan j. noktaya geçiş süresi.

Q: Araç kapasitesi.

$m:$ Araç saylsı.

$q_{i}:$ i. oteldeki müşteri sayısı.

$u_{i}: i$. otel öncesi araçta kalan kapasite.

\subsection{KKARP İçin Çözüm Yöntemleri}

KKARP'de kesin çözüm sonuçlarına ulaşmak oldukça zorlu bir süreçtir. Kesin çözüm sonuçlarını elde etmek için günümüze kadar birçok yöntem geliştirilmiştir. Geliştirilen bu yöntemler Kesin Çözüm Yöntemleri ve Sezgisel Çözüm Yöntemi olmak üzere iki gruba ayrılmaktadır (Laporte, 1992: 356-357). Kesin çözüm yöntemlerinin en iyi çözümü bulmay1 garanti etmesine rağmen her türlü ARP'yi çözebilen kesin bir çözüm yöntemi bulunmamaktadır (Kumar ve Panneerselvam, 2012: 66). Kesin Çözüm Yöntemleri optimal çözüme ulaşmaya olanak sağlarken Sezgisel Çözüm Yöntemleri ise optimale yakın sonuçlar vermektedir. Literatürde dal ve kesme, dal ve sınır algoritmalarıyla beraber dinamik programlama ve küme bölme algoritmalarının kesin çözüm yöntemlerinde kullanıldıkları sıklıkla görülmektedir. Bu yöntemler aşağıdaki şekil 2'de gösterilmiştir (Şahin ve Eroğlu, 2014: 340).

\section{Şekil 2: ARP Çözüm Yöntemleri}

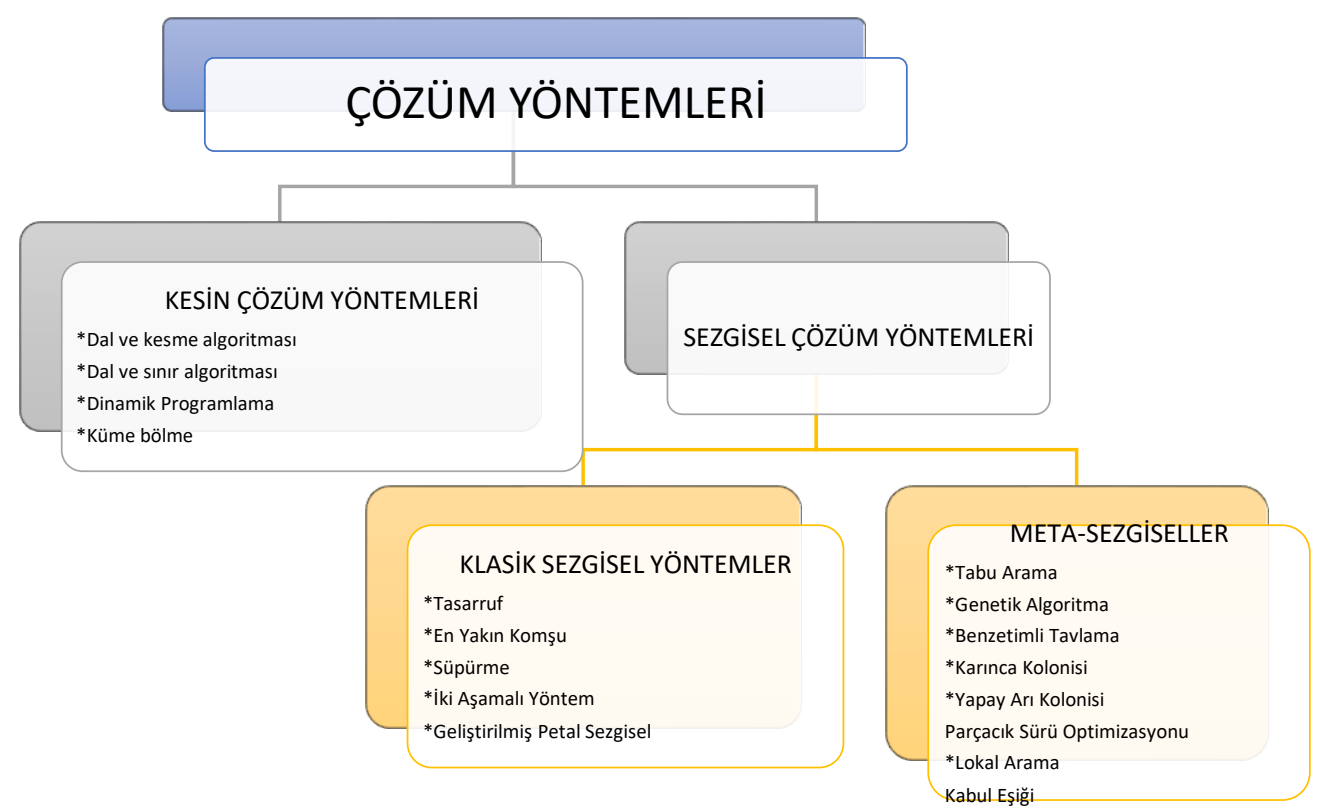

Kaynak: Şahin ve Eroğlu, 2014: 341 
Çözüm yöntemlerinden elde edilmiş çözüm kümesi, her bir araç için en düşük maliyet ve kapasite kısıtlarının korunduğu rotaların oluşturduğu elemanlardan oluşmaktadır (Toth ve Vigo, 2002: 492).

\section{Turizm Sektöründe Araç Rotalama uygulaması}

Çalışmada, turizm sektöründe kendisine ait bir araç filosu ile altmış adet otele hizmet veren "OZANSOY SEYAHAT ACENTASI" adlı firma için önceden belirli otel ve otelden havalimanına gidecek müşteri sayılarına göre oteller ve havalimanı arasında yapılacak turların güzergahlarını en kısa sürede gerçekleşecek şekilde belirleme amaçlanmıştır. Problem KKARP olarak bazı ek kısıtlarla birlikte kesin çözüm verecek şekilde Tamsayılı programlama yaklaşımı ile modellenmiştir. Her biri yirmişer defa olacak şekilde 10 ve 15 otelli tur planları simülasyon yoluyla oluşturulmuş ve firmanın kendi oluşturdukları rotalar ile karar destek sisteminden elde edilen rotaların toplam süresi ve bir yolcunun ortalama ulaşımda geçirdiği süre karşılaştırılmış ve önerilen modelin her iki parametre açısından da önemli iyileştirmeler sağladığı gözlenmiştir.

KKARP için Kara vd. (2004) çalışmalarında MTZ kısıtlarını kullanarak uygun sürede kesin çözüm veren bir model geliştirmişlerdir. Problem, Kara vd. (2004) tarafından kullanılan model temel alınarak ve problemin yapısı gereği bazı ek kısıtlar getirilerek tam sayılı programlama yaklaşımı ile aşağıdaki gibi modellenmiştir.

$$
\left\{\begin{array}{l}
\operatorname{Min} \sum_{i=1}^{n} \sum_{j=1}^{n} C_{i j} x_{i j} \\
\text { kisitlar; } \\
\sum_{j=2}^{n-1} x_{l j}=m \\
\sum_{i=2}^{n-1} x_{i n}=m \\
\sum_{i=2}^{n-1} x_{i j}=1,(j=2, \ldots, n-1, i \neq j) \\
\sum_{j=2}^{n} x_{i j}=1,(i=2, \ldots, n-1, i \neq j) \\
u_{i}-u_{j}+Q x_{i j} \leq Q-q_{j},(i, j=2, \ldots, n-1, i \neq j) \\
q_{i} \leq u_{i} \leq Q,(i=2, \ldots, n-1) \\
1 \leq m \leq\left(\frac{1}{Q} \sum_{i=2}^{n-1} q_{i}\right)+0.999999\left(m \in Z^{+}\right) \\
x_{i j}=0 \text { veya } 1,(i, j=1, \ldots, n, i \neq j)
\end{array}\right.
$$

Modelde yer alan değişken ve parametreler ise aşağıda listelenmiştir.

$x_{i j}: i$. noktadan j. noktaya geçiş yapılması.

$C_{i j}:$ i. noktadan j. noktaya geçiş süresi.

$Q$ : Araç kapasitesi. 
$m:$ Araç sayısı.

$q_{i}:$ i. oteldeki müşteri sayısı.

$u_{i}:$ i. otel öncesi araçta kalan kapasite.

Problemin amaç fonksiyonu (4.1) deki gibi toplam tur süresi minimizasyonunu hedeflemektedir. Kısıt (4.2) ile araç sayısı m kadar firmadan çıkış olması gerektiği ifade edilmiştir. Kısıt (4.3) ile araç sayısı m kadar havalimanına geliş olması gerektiği ifade edilmiştir. Kısıt (4.4) ile her bir otelden j. otele sadece 1 kere geçiş yapılmasına izin verilmiştir. Kısıt (4.5) ile i. otelden her bir otele sadece 1 kere geçiş yapılmasına izin verilmiştir. Kısıt (4.6) ve (4.7) kapasite ve MTZ alt tur eleme için kullanılmıştır. Kısıt (4.8) araç sayısını minimumda tutmak için ekstra olarak modele dahil edilmiştir. Kısıt (4.9) ile karar değişkenlerinin 0-1 tam sayı alması sağlanmıştır. Problem MATLAB programlama dilinde modellenmiş ve çalışmada sadece örnek durumlar için çözüm üretmekle sınırlı kalmayıp, firma için kullanabileceği bir karar destek sistemi oluşturulmuştur.

\subsection{Senaryolar}

Firmadan alınan bilgiler doğrultusunda genellikle bir otelden maksimum 4 yolcu alındığı ve bir tur planında 10 ile 15 civarında otel bulunduğu ifade edilmiştir. Buna göre 10 otel için maksimum 30 yolcu içeren 20 plan ve 15 otel için maksimum 45 yolcu içeren 20 plan oluşturulmuştur.

\section{2. Çözüm}

Problem için üretilen senaryolar firma yetkililerine aktarılmış ve kendilerinden senaryolara göre tur planları yapılması istenmiştir. KKARP modelinden ve firmanın kendi tur planlarından elde edilen tur süreleri ve bir yolcunun araçta geçirdiği ortalama süre 10 otelli turlar için Tablo 1'de, 15 otelli turlar için ise Tablo 2' de bulunmaktadır.

10 otelli planlar için KKARP tur süresi (KKARP-TS) ortalama olarak 166 dakika sürmekte iken Firma tur süresi (Firma-TS) ortalama 179 dakika sürmektedir. Tur süresi tasarrauf oran1 (TSTO) \% 6.86 olarak gerçekleşmiştir. Bir yolcununu ortalama yolda geçirdiği sürelere bakıldığında ise KKARP yolculuk süresi (KKARP-YS) ortalama olarak 60.59 dakika iken Firma yolculuk süresi (Firma-YS) 62.06 dakikadır. Yolculuk süresi tasarruf oranı (YSTO) \% 2.34 olarak gerçekleşmiştir.

15 otelli planlar için KKARP tur süresi (KKARP-TS) ortalama olarak 249 dakika sürmekte iken Firma tur süresi (Firma-TS) ortalama 268 dakika sürmektedir. Tur süresi tasarrauf oranı (TSTO) \% 7.22 olarak gerçekleşmiştir. Bir yolcununu ortalama yolda geçirdiği sürelere bakıldığında ise KKARP yolculuk süresi (KKARP-YS) ortalama olarak 61.6 dakika iken Firma yolculuk süresi (Firma-YS) 61.85 dakikadır. Yolculuk süresi tasarruf oranı (YSTO) \% 0.43 olarak gerçekleşmiştir.

Tur süreleri açısından tüm örnek rotalama planlarında KKARP modeli firmanın kendi oluşturduğu planlarından daha iyi sonuç vermiş̧ir. $\mathrm{Bu}$ da modelin firmaya katkıda bulunacağını göstermektedir. Ayrıca bir yolcunun ortalama yolda geçirdiği sürelerde de azalış gerçekleşmiştir. 
Tablo 1: 10 Otelli Planlar İçin KKARP ve Firma Senaryo Sonuçları

\begin{tabular}{lllllll} 
10lu planlar & KKARP-TS & KKARP-YS & Firma-TS & Firma-YS & TSTO & YSTO \\
\hline 1 & 150 & 59.27 & 155 & 60.14 & 3.23 & 1.44 \\
2 & 151 & 59.34 & 158 & 61.69 & 4.43 & 3.80 \\
3 & 153 & 58.65 & 157 & 58.31 & 2.55 & -0.59 \\
4 & 167 & 64.37 & 174 & 62.56 & 4.02 & -2.90 \\
5 & 178 & 59.50 & 186 & 62.13 & 4.30 & 4.23 \\
6 & 173 & 63.55 & 181 & 64.62 & 4.42 & 1.65 \\
7 & 160 & 55.36 & 162 & 55.96 & 1.23 & 1.07 \\
8 & 164 & 58.91 & 169 & 63.70 & 2.96 & 7.51 \\
9 & 155 & 59.46 & 160 & 59.54 & 3.13 & 0.14 \\
10 & 170 & 59.35 & 178 & 61.35 & 4.49 & 3.26 \\
11 & 158 & 57.27 & 160 & 58.36 & 1.25 & 1.87 \\
12 & 204 & 64.00 & 220 & 65.70 & 7.27 & 2.59 \\
13 & 179 & 63.76 & 203 & 66.16 & 11.82 & 3.63 \\
14 & 169 & 66.39 & 221 & 68.94 & 23.53 & 3.71 \\
15 & 172 & 64.45 & 189 & 63.79 & 8.99 & -1.03 \\
16 & 169 & 60.08 & 220 & 63.92 & 23.18 & 6.00 \\
17 & 164 & 65.36 & 183 & 66.68 & 10.38 & 1.98 \\
18 & 148 & 57.50 & 163 & 58.55 & 9.20 & 1.79 \\
19 & 169 & 56.96 & 170 & 58.73 & 0.59 & 3.01 \\
20 & 168 & 58.20 & 179 & 60.46 & 6.15 & 3.74 \\
Ortalama & 166 & 60.59 & 179 & 62.06 & 6.86 & 2.34 \\
\hline
\end{tabular}

Tablo 2: 15 Otelli Planlar İçin KKARP ve Firma Senaryo Sonuçları

\begin{tabular}{lllllll}
15 li planlar & KKARP-TS & KKARP-YS & Firma-TS & Firma-YS & TSTO & YSTO \\
\hline 1 & 257 & 67.33 & 270 & 66.23 & 4.81 & -1.66 \\
2 & 266 & 65.26 & 302 & 64.69 & 11.92 & -0.88 \\
3 & 259 & 61.19 & 275 & 63.97 & 5.82 & 4.35 \\
4 & 220 & 56.44 & 281 & 59.21 & 21.71 & 4.68 \\
5 & 232 & 59.46 & 276 & 59.46 & 15.94 & 0.00 \\
6 & 242 & 59.03 & 264 & 60.56 & 8.33 & 2.52 \\
7 & 259 & 64.20 & 269 & 64.03 & 3.72 & -0.27 \\
8 & 231 & 56.92 & 257 & 58.87 & 10.12 & 3.31 \\
9 & 237 & 59.03 & 241 & 59.18 & 1.66 & 0.27 \\
10 & 240 & 58.30 & 266 & 60.05 & 9.77 & 2.93 \\
11 & 266 & 64.23 & 277 & 62.43 & 3.97 & -2.88 \\
12 & 255 & 59.77 & 292 & 60.51 & 12.67 & 1.23 \\
13 & 252 & 64.11 & 260 & 63.55 & 3.08 & -0.87 \\
14 & 239 & 62.07 & 254 & 63.59 & 5.91 & 2.38 \\
15 & 246 & 63.48 & 264 & 60.80 & 6.82 & -4.40 \\
16 & 262 & 60.93 & 263 & 61.68 & 0.38 & 1.22 \\
17 & 244 & 62.32 & 257 & 60.77 & 5.06 & -2.55 \\
18 & 246 & 59.03 & 264 & 59.03 & 6.82 & 0.00 \\
19 & 263 & 63.98 & 273 & 64.68 & 3.66 & 1.09 \\
20 & 258 & 64.88 & 264 & 63.71 & 2.27 & -1.84 \\
Ortalama & 249 & 61.60 & 268 & 61.85 & 7.22 & 0.43 \\
\hline
\end{tabular}




\section{Sonuç}

Çalışmada KKARP modeli ile firmanın kendi planlarına göre daha az ortalama tur süreleri elde edilmesi sonucu yakıt maliyetinde azalış meydana gelmiş ve firma karlılığında artış gözlenmiştir. Ayrıca önerilen model ile firma bir gün içerisinde daha fazla tur yapabilir hale gelmiş olması nedeniyle günlük yolcu taşıma kapasitesini arttırmıştır. Bir yolcunun ortalama ulaşımda geçirdiği sürede meydana gelen azalış ile yolcular tarafından firmaya karşı duyulan memnuniyet artmıştır. Oluşturulan karar destek sistemi ile firma, tur hazırlık süresini minimuma indirmiş ve tur planları otomatik hale gelmiştir. Bu sayede firma çalışanları uzun sürede hazırlanan tur planlamalarıyla oluşan büyük bir zahmetten kurtulmuşlar ve işgücü verimliliği artmıştır. Gelecek çalışmalarda karar destek sistemine, havalimanından otellere yolcu transferi gibi amaçlar ve zaman pencere tipi kısıtlar eklenerek firmaya daha fazla katkı yapılması planlanmaktadır. 


\section{KAYNAKÇA}

CLARKE, G., ve WRIGHT, J. W. (1964). Scheduling Of Vehicles From A Central Depot To A Number Of Delivery Points. Operations research, 12(4), 568-581.

CORDEAU, J.F., GENDREAU, M., HERTZ, A., LAPORTE, G., ve SORMANY, J.S., (2004). "New Heuristics For The Vehicle Routing Problem.", Technical Report G2004-33, GERAD, Montreal, Canada.

DANESHZAND, F. (2011). The Vehicle-Routing Problem. Logistics Operations And Management, 8, 127-153.

DANTZIG, G. B., ve RAMSER, J. H. (1959). The Truck Dispatching Problem. Management Science, 6(1), 80-91.

EKSIOGLU, B., VURAL, A. V., ve REISMAN, A. (2009). The Vehicle Routing Problem: A Taxonomic Review. Computers \& Industrial Engineering, 57(4), 1472-1483.

GOLDEN, B. L., ve STEWART, W. R. (1978). Vehicle routing with probabilistic demands. In Computer Science and Statistics: Tenth Annual Symposium on the Interface, NBS Special Publication (Vol. 503, pp. 252-259).

GOLDEN, B. L., MAGNANTI, T. L., ve NGUYEN, H. Q. (1972). Implementing Vehicle Routing Algorithms. Networks, 7(2), 113-148.

KARA, I., LAPORTE, G., ve BEKTAS, T. (2004). A Note On The Lifted Miller-TuckerZemlin Subtour Elimination Constraints For The Capacitated Vehicle Routing Problem. European Journal Of Operational Research, 158(3), 793-795.

KARAGÜL, K., ve GÜNGÖR, İ. (2014a). Havalimanindan Otellere Tek Tip Araçlarla Turist Dağitimi Problemine Çözüm Önerisi Ve Alanya Uygulamasi. Dumlupinar University Journal Of Social Science/Dumlupinar Üniversitesi Soysyal Bilimler Dergisi.

KARAGUL, K., ve GÜNGÖR, İ. (2014b). A Case Study Of Heterogeneous Fleet Vehicle Routing Problem: Touristic Distribution Application In Alanya. An International Journal of Optimization and Control, 4(2), 67.

KUMAR, S. N., ve PANNEERSELVAM, R. (2012). A Survey On The Vehicle Routing Problem And Its Variants. Intelligent Information Management, 4(03), 66.

LAPORTE, G. (1992). The Vehicle Routing Problem: An Overview Of Exact And Approximate Algorithms. European journal of operational research, 59(3), 345-358.

LEVIN, A. (1971). Scheduling And Fleet Routing Models For Transportation Systems. Transportation Science, 5(3), 232-255.

LIN, S. W., LEE, Z. J., YING, K. C., ve LEE, C. Y. (2009). Applying Hybrid MetaHeuristics For Capacitated Vehicle Routing Problem. Expert Systems With Applications, 36(2), 1505-1512.

ŞAHIN, Y., ve EROĞLU, A. (2014). Kapasite Kısıtll Araç Rotalama Problemi İçin Metasezgisel Yöntemler: Bilimsel Yazın Taraması. Süleyman Demirel Üniversitesi İktisadi ve İdari Bilimler Fakültesi Dergisi, 19(4).

SOLOMON, M. (1983). Vehicle Routing And Scheduling With Time Window Constraints: Models and algorithms. Technical report, College of Business Admin. Northeastern University, No. 83-42. 
TOTH, P., ve VIGO, D. (2002). Models, relaxations and exact approaches for the capacitated vehicle routing problem. Discrete Applied Mathematics, 123(1), 487512.

YÜCENUR, G. N., ve DEMIREL, N. Ç. (2011). A Hybrid Algorithm With Genetic Algorithm And Ant Colony Optimization For Solving Multi-Depot Vehicle Routing Problems. Journal of Engineering and Natural Sciences, 340-350. 